\title{
Influence of mild cold on 24 h energy expenditure in 'normally' clothed adults
}

\author{
BY P. M. WARWICK AND R. BUSBY \\ Department of Biochemistry, Microbiology and Nutrition, University of New England, Armidale, \\ New South Wales 235I, Australia
}

(Received 3 August 1989 - Accepted 15 November 1989)

\begin{abstract}
Ten subjects aged 19-35 years (four men and six women) underwent two measurements of $24 \mathrm{~h}$ energy expenditure (EE) in a whole-body respiration calorimeter, one at a temperature of $28^{\circ}$ and one at $20^{\circ}$. Choice of clothing was allowed. Dietary intake was standardized and subjects were asked to follow the same pattern of activity during both measurements. Mean $24 \mathrm{~h}$ EE was significantly greater at the cooler temperature by 5.0 (SD 5.5) \%, with individual differences ranging from $4.6 \%$ lower to $12.6 \%$ higher. The difference in $\mathrm{EE}$ at the two temperatures was similar during the day and the night and occurred even though subjects wore more clothes and used more bedding at $\mathbf{2 0}^{\circ}$. No relationship was observed between response to $\mathbf{2 0}^{\circ}$ and body-weight status. In conclusion, the assumption that mild cold is unlikely to affect $\mathrm{EE}$ in subjects wearing normal clothing may be incorrect.
\end{abstract}

Energy expenditure: Environmental temperature

It is well established that energy expenditure (EE) increases during acute exposure to severe cold ( $15^{\circ}$ or less) and that this is largely due to shivering (Buskirk et al. 1960, 1963; Iampietro et al. 1960; Wyndham et al. 1968; Rochelle \& Horvath, 1969; Bittel, 1987; Young et al. 1989). Mild cold also increases EE in lightly-clad subjects in the absence of shivering (Iampietro et al. 1960; Quaade, 1963; Dauncey, 1981; Blaza \& Garrow, 1983). Several workers have suggested that cold exposure is of little practical importance as a factor affecting EE since effects of cold are minimized by adjustments to clothing or heating, or both (Food and Health Organization/World Health Organization/United Nations University, 1985; James, 1985) and if people are given the chance they do not expose themselves to cold severe enough to induce a metabolic response (Garrow, 1978). However, De Boer et al. (1988) found a lower EE in a group of normally clothed men housed in a calorimeter at $24.5^{\circ}$ compared with another group measured at $21.0^{\circ}$, and postulated that mild cold might also affect subjects allowed to change clothes according to their perception of temperature. Since little is known about the effects of mild cold in 'normally' clothed subjects, the aim of the present study was to investigate whether mild cold increases $24 \mathrm{~h} \mathrm{EE}$ in subjects confined in a respiration chamber and allowed to choose their own clothing.

\section{METHODS}

Subjects and protocol

Ten healthy subjects (six females, four males; all non-smokers) were recruited from university student and staff volunteers. All subjects underwent two measurements of $24 \mathrm{~h}$ EE in a whole-body respiration calorimeter, one at a temperature of $28^{\circ}$ and one at $20^{\circ}$. The order of measurements was randomized. In women, the two measurements were done either 1 month apart or within the same week to minimize effects of the menstrual cycle. In men, both measurements were done within a 6-week period. All subjects were instructed 
to take a variety of clothing into the calorimeter to ensure a choice of "normal' clothing at each temperature. Ample bedding was supplied. The amount of clothing worn and bedding used was recorded. Dietary intake was standardized and subjects were asked to follow the same pattern of activity during both measurements. Subjects were asked to ensure that their activity and dietary intake were similar during the day before each calorimetry measurement. The study protocol was approved by the Ethics Committee of this University.

\section{Basal metabolic rate $(B M R)$}

BMR was measured directly after each calorimetry measurement in a ventilated hood apparatus as described previously (Warwick et al. 1987). All measurements were done at least $12 \mathrm{~h}$ after the last meal, in a room held at a temperature of $25-28^{\circ}$.

\section{Body-weight}

Body-weight was measured directly after each calorimetry measurement using a beam balance capable of weighing to within $50 \mathrm{~g}$. All measurements were made before breakfast, with an empty bladder and wearing similar clothes.

\section{$24 h E E$}

The $24 \mathrm{~h}$ EE was measured using a whole-body respiration calorimeter as described previously (Warwick et al. 1988), except that in the present study subjects were studied at ambient temperatures of $28^{\circ}$ and $20^{\circ}$, and the following equation was used to calculate EE from gaseous exchange and urinary nitrogen excretion (Brockway, 1987):

$$
\mathrm{EE}(\mathrm{kJ})=16.58 \mathrm{O}_{2} \text { (litres) }+4.51 \mathrm{CO}_{2}(\text { litres })-5.90 \mathrm{~N}(\mathrm{~g}) \text {. }
$$

Air velocity in the calorimeter was lower than $0.2 \mathrm{~m} / \mathrm{s}$ with velocities of $0.18 \mathrm{~m} / \mathrm{s}$ under the desk and $0.13 \mathrm{~m} / \mathrm{s}$ on the bed (measured by anemometer). Relative humidity averaged $53 \%$ at $28^{\circ}$ and $56 \%$ at $20^{\circ}$ and varied between 40 and $60 \%$ at both temperatures. The function of the calorimeter was tested by combustion of ethanol and was found to be accurate to within $1.5 \%$ at both temperatures.

Eight subjects spent adaptive nights in the calorimeter (i.e. entered the calorimeter at 20.00 hours) with $24 \mathrm{~h}$ EE measurements commencing at 08.00 hours the next morning. Two subjects who were familiar with the calorimetry measurements arrived at the laboratory in time to enter the calorimeter at 08.00 hours

\section{Dietary intake}

Dietary intake during the $24 \mathrm{~h}$ EE measurements was calculated using food composition tables (Thomas \& Corden, 1977) to provide a daily energy intake of about 1.27 times the BMR of each subject as measured before the start of the study. Diets provided on average 20,26 and $54 \%$ of energy from protein, fat and carbohydrate respectively with a food quotient of $0 \cdot 88$. Meals were served at $08.00,13.00$ and 18.00 hours, with additional snacks if desired. Coffee and tea were allowed as desired. All subjects consumed the same diet (and coffee and tea) during both of the calorimetry measurements.

\section{Level of activity}

All subjects were asked to follow the same (self chosen) pattern of sedentary activities during each of the $24 \mathrm{~h}$ EE measurements, and to keep mir ute-by-minute activity records. Activities were grouped into the following categories and assigned a code: asleep, lying quietly, sitting quietly, sitting busy, and standing activites. Exercise was not allowed. Subjects were asked to be settled in bed by 23.00 hours and :o stay lying quietly in bed until 
Table 1. Characteristics, basal metabolic rate (BMR) and treatment details of subjects

\begin{tabular}{|c|c|c|c|c|c|c|c|c|c|c|}
\hline \multirow{3}{*}{$\begin{array}{c}\text { Subject } \\
\text { no. }\end{array}$} & \multirow[b]{3}{*}{ Sex } & \multirow{3}{*}{$\begin{array}{c}\text { Age } \\
\text { (years) }\end{array}$} & \multirow{3}{*}{$\begin{array}{l}\text { Height } \\
\text { (m) }\end{array}$} & \multirow{2}{*}{\multicolumn{2}{|c|}{$\mathrm{Wt}^{*}(\mathrm{~kg})$}} & \multirow{3}{*}{$\begin{array}{c}\text { Body } \\
\text { mass } \\
\text { index } \dagger\end{array}$} & \multirow{2}{*}{\multicolumn{2}{|c|}{$\mathrm{BMR}^{*}(\mathrm{MJ} / \mathrm{d})$}} & \multicolumn{2}{|c|}{ Treatment details } \\
\hline & & & & & & & & & \multirow{2}{*}{$\begin{array}{c}\text { First } \\
\text { treatment }\end{array}$} & \multirow{2}{*}{$\begin{array}{l}\text { Season } \\
\text { studied }\end{array}$} \\
\hline & & & & $28^{\circ}$ & $20^{\circ}$ & & $28^{\circ}$ & $20^{\circ}$ & & \\
\hline 1 & $3^{*}$ & 20 & 1.82 & $68 \cdot 2$ & $68 \cdot 0$ & $20 \cdot 6$ & $6 \cdot 76$ & $6 \cdot 75$ & $20^{\circ}$ & Early spring \\
\hline 2 & $\hat{\jmath}$ & 25 & 1.76 & $68 \cdot 0$ & 67.9 & $21 \cdot 9$ & $7 \cdot 66$ & 7.93 & $28^{\circ}$ & Early spring \\
\hline 3 & t & 35 & 1.69 & $65 \cdot 8$ & $66 \cdot 1$ & $23 \cdot 1$ & $6 \cdot 12$ & 5.97 & $20^{\circ}$ & Mid-spring \\
\hline 4 & ? & 19 & 1.64 & $66 \cdot 6$ & $66 \cdot 5$ & $24 \cdot 7$ & $5 \cdot 80$ & $5 \cdot 49$ & $20^{\circ}$ & Late autumn \\
\hline 5 & q & 19 & 1.69 & $66 \cdot 8$ & $66 \cdot 5$ & $23 \cdot 3$ & 6.66 & $6 \cdot 48$ & $28^{\circ}$ & Mid-spring \\
\hline 6 & $\vec{s}$ & 21 & 1.80 & $79 \cdot 3$ & $80 \cdot 2$ & $24 \cdot 6$ & $7 \cdot 62$ & $7 \cdot 78$ & $28^{\circ}$ & Late summer \\
\hline 7 & q & 21 & 1.66 & $77 \cdot 4$ & 77.5 & $28 \cdot 1$ & $6 \cdot 20$ & $6 \cdot 60$ & $20^{\circ}$ & Early autumn \\
\hline 8 & $q$ & 22 & 1.65 & $112 \cdot 3$ & $112 \cdot 3$ & $41 \cdot 2$ & $7 \cdot 44$ & $7 \cdot 33$ & $28^{\circ}$ & Early autumn \\
\hline 9 & 9 & 20 & 1.67 & $101 \cdot 0$ & $100 \cdot 0$ & $36 \cdot 0$ & $7 \cdot 49$ & $7 \cdot 83$ & $20^{\circ}$ & Late autumn \\
\hline 10 & $\delta^{*}$ & 29 & 1.78 & $103 \cdot 8$ & $102 \cdot 7$ & $32 \cdot 6$ & $9 \cdot 32$ & $9 \cdot 04$ & $28^{\circ}$ & Late autumn \\
\hline Mean & - & $23 \cdot 1$ & $1 \cdot 72$ & $80 \cdot 9$ & $80 \cdot 8$ & $27 \cdot 6$ & $7 \cdot 11$ & $7 \cdot 12$ & - & - \\
\hline $\mathrm{SD}$ & - & $5 \cdot 2$ & 0.07 & $17 \cdot 9$ & $17 \cdot 7$ & $6 \cdot 8$ & $1 \cdot 03$ & $1 \cdot 11$ & - & - \\
\hline
\end{tabular}

* After $28^{\circ}$ and $20^{\circ}$ calorimetry measurements.

$\uparrow$ Weight $(\mathrm{kg}) /$ height $(\mathrm{m})^{2}$.

called at 08.00 hours. Overall levels of activity were calculated as multiples of BMR from time periods spent in each activity category and their average energy costs as described previously (Warwick et al. 1988). The energy costs used in the present study were: asleep or lying quietly overnight (24.00-08.00 hours) $1.0 \times$ BMR; asleep, lying or sitting quietly during the day and evening, $1.2 \times \mathrm{BMR}$; sitting busy $1.5 \times \mathrm{BMR}$; standing activities $2.5 \times$ BMR.

\section{Statistical analysis}

All data manipulation and statistical analysis were done using the Minitab package (Ryan et al. 1985). Significance of differences was assessed by paired $t$ tests.

\section{RESULTS}

The physical characteristics, BMR and treatment details of the subjects are shown in Table 1. Six subjects had a body mass index (BMI) in the range $20-25$, one in the range $25-30$, and three greater than 30 . Body-weight was stable to within about $1 \mathrm{~kg}$ and mean bodyweight was the same after both calorimetry measurements. Mean BMR was the same after the $28^{\circ}$ and $20^{\circ}$ measurements $(7.11$ (SD 1.03 ) and 7.12 (SD 1.11$) \mathrm{MJ} / \mathrm{d}$ respectively) and after the first and second measurements $(7.09$ (SD 1.00) and 7.13 (SD 1.08) $\mathrm{MJ} / \mathrm{d}$ respectively). Individual coefficients of variation for the two BMR measurements averaged $1.6 \%$ (range $0 \cdot 1-3 \cdot 1 \%$ ).

Table 2 shows the individual and mean results for EE, energy intake, respiratory quotient (RQ) and activity level of each subject during the two calorimetry measurements. The $24 \mathrm{~h}$ EE results have also been expressed as multiples of mean BMR, and have been subdivided into overnight (24.00 08.00 hours) and daytime (08.00-24.00 hours) EE.

On average $24 \mathrm{~h} \mathrm{EE}$ was $5 \%$ higher during the $20^{\circ}$ than the $28^{\circ}$ measurement period $(P<0.02)$ with individual differences ranging from $4.6 \%$ lower to $12.6 \%$ higher. Daytime EE and overnight EE were also higher at $20^{\circ}(P<0.05)$. During the day, individual differences ranged from $7 \cdot 7 \%$ lower to $15.8 \%$ higher at $20^{\circ}$, while overnight they ranged from $0.8 \%$ lower to $8.9 \%$ higher. 
P. M. WARWICK AND R. BUSBY

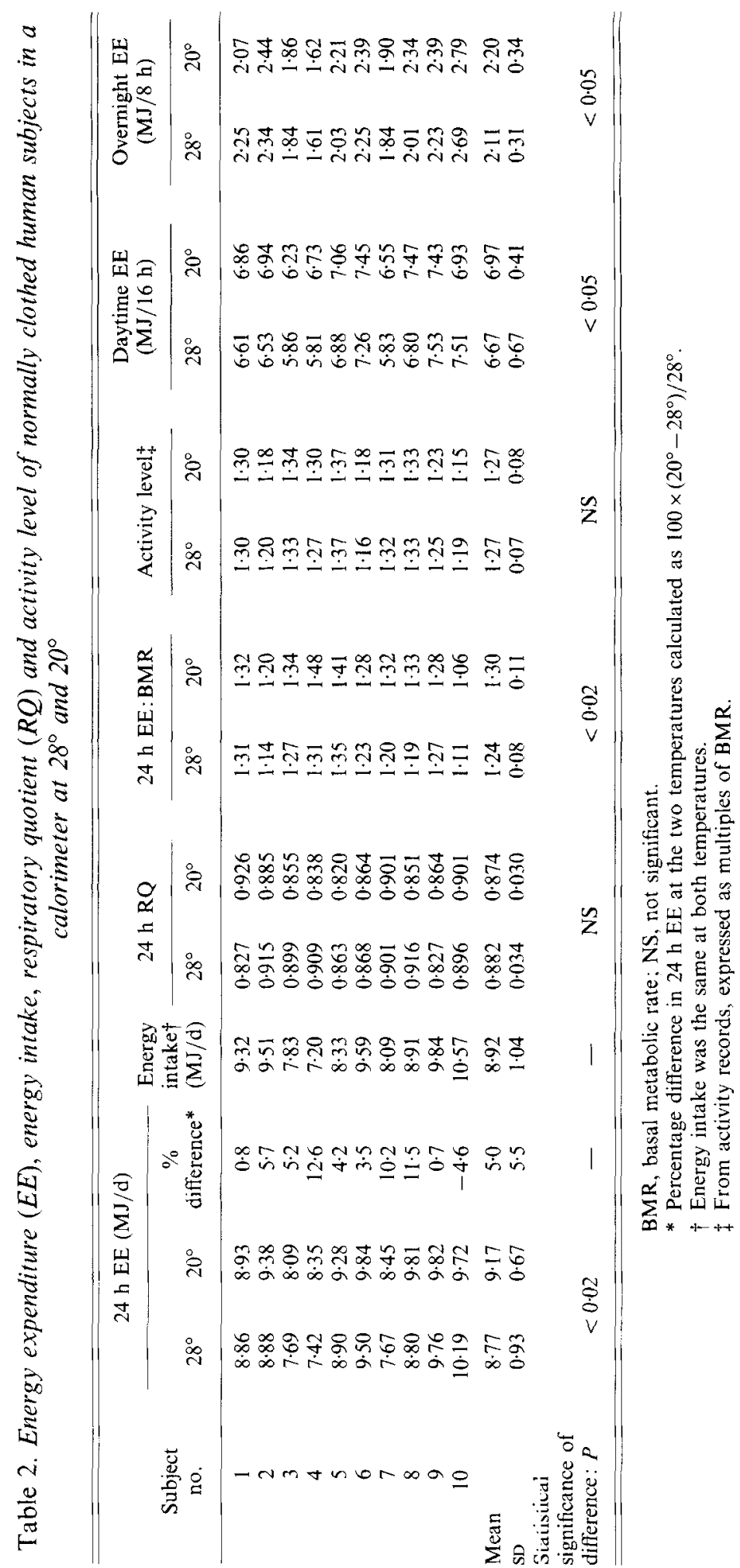


Table 3. Temperature preference, clothing worn and bedding used by normally clothed human subjects during $28^{\circ}$ and $20^{\circ}$ measurements in the calorimeter

\begin{tabular}{|c|c|c|c|c|c|}
\hline \multirow{2}{*}{$\begin{array}{c}\text { Subject } \\
\text { no. }\end{array}$} & \multirow{2}{*}{$\begin{array}{c}\text { Temperature } \\
\text { preference }\end{array}$} & \multicolumn{2}{|c|}{ Clothing worn (daytime)* } & \multicolumn{2}{|c|}{ Bedding used (at night)* } \\
\hline & & $28^{\circ}$ & $20^{\circ}$ & $28^{\circ}$ & $20^{\circ}$ \\
\hline 1 & $28^{\circ}$ & $s+t$ & $\mathrm{Tr}+4 \mathrm{~T}$ & $S(+B)$ & $\mathrm{S}+3 \mathrm{~B}$ \\
\hline 2 & $28^{\circ}$ & $s+t$ & $\mathrm{Tr}+2 \mathrm{~T}$ & $\mathrm{~S}$ & $S+2 B$ \\
\hline 3 & $20^{\circ}$ & $s+t$ & $\mathrm{Tr}+34 \mathrm{~T}$ & $S(+C)$ & $C+1 B$ \\
\hline 4 & $28^{\circ}$ & $s+t$ & $\mathrm{Tr}+2 \mathrm{~T}$ & $S(+B)$ & $S+3 B$ \\
\hline 5 & $20^{\circ}$ & $s+t$ & $\mathrm{Tr}+2 \mathrm{~T}$ & $\mathrm{~S}$ & $S+3-4 B$ \\
\hline 6 & $20^{\circ}$ & $s+t$ & $\mathbf{s}+1 \mathrm{~T}+\mathbf{B}$ & $\mathrm{S}$ & $S+1 B$ \\
\hline 7 & $20^{\circ}$ & $s+t$ & $\mathrm{Tr}+2 \mathrm{~T}$ & $S(+C)$ & $\mathrm{C}$ \\
\hline 8 & $20^{\circ}$ & $s+t$ & $\mathrm{Tr}+2-3 \mathrm{~T}$ & $\mathrm{~S}$ & $\mathrm{~S}+2-3 \mathrm{~B}$ \\
\hline 9 & $28^{\circ}$ & $s+t$ & $\mathrm{Tr}+2 \mathrm{~T}$ & $\mathbf{S}$ & $S+3 B$ \\
\hline 10 & $20^{\circ}$ & $s+t$ & $\mathrm{Tr}+1 \mathrm{~T}$ & $\mathrm{~S}$ & $S+3 B$ \\
\hline
\end{tabular}

* $s+t$, Light shorts or skirt (s) and t-shirt (t) with sandals; Tr, long trousers with shoes and socks; T, top garments; 1T, one garment; 2T, two garments, etc.; B, blanket; 1B, one blanket; 2B, two blankets etc.; (subject no. 6 wrapped a blanket around himself); $\mathrm{S}$, sheet; $\mathrm{C}$, continental quilt; (C) or (B), continental quilt or blanket used during part of the night only.

On average the group was slightly but not significantly in negative energy balance during the $20^{\circ}$ measurement and in positive balance during the $28^{\circ}$ measurement. RQ did not vary with temperature, averaging 0.882 (SD 0.03 ) and 0.874 (SD 0.03 ) over the $24 \mathrm{~h}$. The mean $24 \mathrm{~h} \mathrm{RQ}$ was similar to the food quotient of the dietary intake.

The mean $24 \mathrm{~h}$ EE: BMR ratio was 1.24 (SD 0.08) at $28^{\circ}$ and 1.30 (SD 0.11 ) at $20^{\circ}$ $(P<0.02)$, while the mean recorded activity level was 1.27 (SD 0.07-0.08) at both temperatures. On average, subjects spent $14 \mathrm{~h}$ lying quietly or asleep, $2.5 \mathrm{~h}$ sitting quietly, $6.5 \mathrm{~h}$ sitting busy and $1 \mathrm{~h}$ in standing activities. Only two subjects recorded different activity patterns between the two temperatures. Subject no. 4 was less active at $28^{\circ}$, spending $0.5 \mathrm{~h}$ less time on foot and $0.5 \mathrm{~h}$ more time lying quietly. Subject no. 10 was less active at $20^{\circ}$, spending $0.5 \mathrm{~h}$ less time on foot, $6.5 \mathrm{~h}$ less time sitting quietly and $7 \mathrm{~h}$ more time lying quietly or asleep during the day.

Table 3 shows the temperature preference of each subject and the clothing worn and bedding used at each temperature. Four subjects preferred $28^{\circ}$ while six preferred $20^{\circ}$. All subjects wore more clothing and used more bedding at the cooler temperature. All subjects reported sleeping well during the overnight measurement except for subject no. 3 who felt too hot at $28^{\circ}$.

\section{DISCUSSION}

The present study has shown that $24 \mathrm{~h}$ EE in normally clothed subjects in a whole-body respiration calorimeter is significantly greater at an ambient temperature of $20^{\circ}$ than at $28^{\circ}$. The increase in $\mathrm{EE}$ at $20^{\circ}$ was similar during the day and the night and occurred even though all subjects wore more clothes and used more bedding than at $28^{\circ}$. The mean increase was small, only $5 \%$, but not necessarily negligible if considered as an additive effect on EE over a prolonged period of time. These results call into question the assumption that mild cold is unlikely to affect EE in subjects kept insulated by clothing or blankets (Food and Agriculture Organization/World Health Organization/United Nations University, 1985; Warwick et al. 1987).

There are few other studies of effects of mild cold on $24 \mathrm{~h}$ EE with which to compare our results. De Boer et al. (1988) noted a lower $24 \mathrm{~h}$ EE in a group of normally clothed men 
housed in a calorimeter at $24 \cdot 5^{\circ}$ compared with another group housed at $21^{\circ}$, although their study was not designed to investigate effects of temperature. Dauncey (1981) observed a $7 \%$ increase in $24 \mathrm{~h} \mathrm{EE}$ in nine lightly-clad, normal-weight women at a temperature of $22^{\circ}$ compared with $28^{\circ}$. Blaza \& Garrow (1983) observed a similar increase in five lightly-clad, normal-weight women at $23^{\circ}$ compared with $25-26^{\circ}$, although $24 \mathrm{~h}$ EE in five obsese women tended to be lower at the cooler temperature (Blaza \& Garrow, 1983). Direct comparison of these results with the $5 \%$ increase observed in the present study is not possible because our temperature difference was greater, our subjects wore extra clothing at $20^{\circ}$ and we included males and obese subjects in the study. However, the range of individual variation in response to the cooler temperature ir the present study is within the ranges observed by Dauncey (1981) and Blaza \& Garrow 1983).

Unlike Blaza \& Garrow (1983) we did not observe a difference in mean response between our six normal-weight and our four obese subjects, although the range of individual response was larger in our obese subjects. Other studies have also observed variable effects of short-term exposure to mild cold in obese subjects which may be explained by different 'types' of obesity (Quaade, 1963, 1973; Lean \& Murgatroyd, 1987).

The reason for the response to cold even in normally clothed subjects and for individual variations in response is not clear. None of our subjects reported shivering, although most said they felt cool at $20^{\circ}$. Feelings of coldness and physiological response to cold could be influenced by choice of clothing, but we could find no obvious relationship between clothing worn or blankets used and responses in our subjects.

Some of the individual variation in response may have been due to 'normal' intraindividual variation in $24 \mathrm{~h}$ EE. This averages $1-3 \%$ for measurements with standardized activities (Dallosso et al. 1982; Garby et al. 1984; De Boer ei al. 1987) and 3-5\% in subjects following sedentary but not standardized activity patterns (Warwick et al. 1988). Effects of familiarization with the calorimeter may also have contrib ted to individual variations in response, although most subjects spent an adaptive night in the chamber before their $24 \mathrm{~h}$ EE measurements, and an effect of treatment order was not found in a previous study (Warwick et al. 1988). Some of the individual variation in the present study may have been due to recorded (or unrecorded) differences in activity between the two measurements. For example, the negative response in subject no. 10 , and the highest response in subject no. 4 may be partly explained by altered activity patterns which orcurred even though all subjects had been asked to follow the same activity pattern and were required to keep activity records as a check.

However, as treatment order was randomized, the mean recorded activity level was the same at both temperatures, and the increase in EE was similar during the day and the night. The greater mean $24 \mathrm{~h} \mathrm{EE}$ at $20^{\circ}$ cannot be explained by treatment order or by obvious changes in level of activity. The possibility remains, however, that small differences in alertness, movement, or muscle tone occurred between the two measurements which would not have been noted on activity records.

Another explanation for the effect of mild cold on EE is through stimulation of metabolic processes independent of muscular contraction (Landsberg et al. 1984). These processes are influenced by the hormonal milieu and several studies have linked thermoregulatory capacity to the activity of the sympathetic nervous system or thyroid hormones, or both (Landsberg et al. 1984; Beard \& Borel, 1988; Lean \& Murgatroyd, 1988). We did not test our subjects for thyroid function or catecholamine excretion so we do not know whether variations in these factors influenced individual responses in the present study.

A number of other factors have been shown to influence metabolic response to severe cold. These include level of fatness (Daniels \& Baker, 1961: Wyndham et al. 1968; Buskirk et al. 1963; Bittel, 1987), level of physical fitness (Bittel et al. 1988), acclimatization to cold 
(Scholander et al. 1958) and level of food intake (Quaade, 1963, 1973; Brooke et al. 1973; Fellows et al. 1985). It is not known if these factors also influence the response to mild cold. However, in the present study there was no obvious relationship between response to mild cold and season studied, only two subjects (nos. 3 and 5) undertook any regular exercise and both of these showed intermediate responses, and body-weight was stable between measurements suggesting energy balance. All subjects had also been asked to standardize their dietary intake and activity on the day before the calorimetry measurements to minimize possible effects of previous diet or exercise.

In conclusion, the results of the present study suggest that mild cold increases EE in subjects wearing normal clothing and that temperature effects may need to be taken into account when estimating $\mathrm{EE}$ and energy requirements in humans.

\section{REFERENCES}

Beard, J. \& Borel, M. (1988). Iron deficiency and thermoregulation. Nutrition Today 23, 41-45.

Bittel, J. H. M. (1987). Heat debt as an index for cold adaptation in men. Journal of Applied Physiology 62, $1627-1634$.

Bittel, J. H. M., Nonotte-Varly, C., Livechi-Gonnet, G. H., Savourey, G. L. M. J. \& Hanniquet, A. M. (1988). Physical fitness and thermoregulatory reactions in a cold environment in men. Journal of Applied Physiology $\mathbf{6 5}$, 1984-1989

Blaza, S. \& Garrow, J. S. (1983). Thermogenic response to temperature, exercise and food stimuli in lean and obese women, studied by $24 \mathrm{~h}$ direct calorimetry. British Journal of Nutrition 49, 171-180.

Brockway, J. M. (1987). Derivation of formulae used to calculate energy expenditure in man. Human Nutrition: Clinical Nutrition 41C, 463-471.

Brooke, O. G., Harris, M. \& Salvosa, C. B. (1973). The response of undernourished babies to cold. Journal of Physiology 233, 75-91.

Buskirk, E. R., Thompson, R. H., Moore, R. \& Whedon, G. D. (1960). Human energy expenditure studies in the National Institute of Arthritis and Metabolic diseases metabolic chamber. I. Interaction of cold environment and specific dynamic effect II : sleep. American Journal of Clinical Nutrition 8, 602-613.

Buskirk, E. R., Thompson, R. H. \& Whedon, G. D. (1963). Metabolic response to cold air in men and women in relation to total body fat content. Journal of Applied Physiology 18, 603-612.

Dallosso, H. M., Murgatroyd, P. R. \& James, W. P. T. (1982). Feeding frequency and energy balance in young men. Human Nutrition: Clinical Nutrition 36C, 25-39.

Daniels, F. \& Baker, P. T. (1961). Relationship between body fat and shivering in air at $15^{\circ} \mathrm{C}$. Journal of Applied Physiology 16, 421-425.

Dauncey, M. J. (1981). Influence of mild cold on $24 \mathrm{~h}$ energy expenditure, resting metabolism and diet-induced thermogenesis. British Journal of Nutrition 45, 257-267.

De Bocr, J. O., Van Es, A. J. H., Vogt, J. E., Van Raaij, J. M. A. \& Hautvast, J. G. A. G. (1987). Reproducibility of 24 h energy expenditure measurements using a whole body indirect calorimeter. British Journal of Nutrition 57, $201-209$.

De Boer, J. O., Van Es, A. J. H., Voorrips, I. E., Blokstra, F. \& Vogt, J. E. (1988). Energy metabolism and requirements in different ethnic groups. European Journal of Clinical Nutrition 42, 983 . 997.

Fellows, I. W., MacDonald, I. A., Bennett, T. \& Allison, S. P. (1985). The effect of undernutrition on thermoregulation in the elderly. Clinical Science 69,525 -532.

Food and Health Organization/World Health Organization/United Nations University (1985). Energy and protein requirements. WHO Technical Report Series no. 724. Geneva: WHO.

Garby, L., Lammert, O. \& Nielsen, E. (1984). Within-subjects between-weeks variation in 24-hour energy expenditure for fixed physical activity. Human Nutrition: Clinical Nutrition 38C, 39l-394.

Garrow, J. S. (1978). Energy Balance and Ohesity in Man, 2nd ed. Amsterdam: Elsevier.

lampietro, P. F., Vaughan, J. A., Goldman, R. F., Kreider, M. B., Masuce, F. \& Bass, D. (1960), Heat production from shivering. Journal of Applied Physiology 15, 632-634.

James, W. P. T. (1985). Comments on the new equations. Human Nutrition: Clinical Nutrition 39C, Suppl. 1, 9296.

Landsberg, L., Savillc, M. E. \& Young, J. B. (1984). Sympathoadrenal system and regulation of thermogenesis. American Journal of Physiology 247, E181-EI89.

Lean, M. E. J. \& Murgatroyd, P. R. (1987). Defective thermogenic response to mild cold exposure in type II diabetes and Cushing's disease. Proceedings of the Nutrition Society 46, I8A.

Lean, M. E. J. \& Murgatroyd, P. R. (1988). Thyroid involvement in metabolic responses to mild cold is impaired in obese diabetic women. Proceedings of the Nutrition Society 47, 134A.

Quaade, F. (1963). Insulation in leanness and obesity. Lancet ii, 429-432. 
Quaade, F. (1973). Thermoregulatory disturbances as causative and maintaining factors in leanness and obesity. The 'homeothermic' theory. In Energy Balance in Man, pp. 135-140 (M. Apfelbaum, editor). Paris: Masson et cie.

Rochelle, R. H. \& Horvath, S. M. (1969). Metabolic responses to food and acute cold stress. Journal of Applied Physiology 27, 710-714.

Ryan, T. A., Joiner, B. L. \& Ryan, B. F. (1985). Minitab Reference Manucl. University Park, PA: Minitab Inc. Scholander, P. F., Hammel, H. T., Lange Anderson, K.\& Loyning, Y. (1958). Metabolic acclimation to cold in man. Journal of Applied Physiology 12, 1-8.

Thomas, S. \& Corden, M. (1977). Metric Tables of Composition of Auitralian Foods. Canberra: Australian Government Publishing Service.

Warwick, P. M., Chapple, R. S. \& Thomson, E. S. (1987). The effect of smoking two cigarettes on resting metabolic rate with and without food. International Journal of Obesity 11, 229-237.

Warwick, P. M., Edmundson, H. M. \& Thomson, E. S. (1988). Prediction of energy expenditure: simplified FAO/WHO/UNU factorial method versus continuous respirometry and habitual energy intake. American Journal of Clinical Nutrition 48, $1188-1196$.

Wyndham, C. H., Williams, C. G. \& Loots, H. (1968). Reactions to co d. Journal of Applied Physiology 24, $282-287$.

Young, A. J., Sawka, M. N., Neufer, P. D., Muza, S. R., Askew, E. W. \& Pandolf, K. B. (1989). Thermoregulation during cold water immersion is unimpaired by low muscle glycogen levels. Journal of Applied Physiology 66. $1809-1816$. 